\title{
Phytochemicals characterization of nutraceutical enriched fruits and nuts spread
}

\section{Rohini*}

Department of Food Science and Nutrition, Community Science College and Research Institute, Tamil Nadu Agricultural University, Madurai - 625104 (Tamil Nadu), India

\section{P. S. Geetha}

Department of Differently Abled Studies, Community Science College and Research Institute, Tamil Nadu Agricultural University, Madurai - 625104 (Tamil Nadu), India

\section{R. Vijayalakshmi}

Department of Food Science and Nutrition, Community Science College and Research Institute, Tamil Nadu Agricultural University, Madurai - 625104 (Tamil Nadu), India

M. L. Mini

Department of Biotechnology, Agricultural College and Research Institute, Tamil Nadu Agricultural University, Madurai - 625104 (Tamil Nadu), India

${ }^{*}$ Corresponding author. Email: rohinichelliah96@gmail.com

\section{How to Cite}

Rohini, C. et al. (2021). Phytochemicals characterization of nutraceutical enriched fruits and nuts spread. Journal of Applied and Natural Science, 13 (SI), 124 - 129. https://doi.org/10.31018/jans.v13iSI.2810

\section{Article Info} jans.v13iSI.2810

Received: March 22, 2021

Revised: May 14, 2021

Accepted: June 3, 2021 https://doi.org/10.31018/

\begin{abstract}
The present study aimed to formulate a nutraceutical enriched fruits and nuts spreads and analyze the presence of phytochemicals in the formulated spread. The pumpkin seeds and cucumber seeds were roasted at $150^{\circ} \mathrm{C}$ for 15 mins and made into powder. The seed powder was mixed to the pulp of $\beta$-carotene rich fruits like mango, papaya and muskmelon in order to make fruits and nuts spread. Treatments like Mango with pumpkin seed powder $\left(T_{1}\right)$, Papaya with pumpkin seed powder $\left(T_{2}\right)$, Muskmelon with pumpkin seed powder $\left(T_{3}\right)$, Mango with cucumber seed powder $\left(T_{4}\right)$, Papaya with cucumber seed powder $\left(T_{5}\right)$ and Muskmelon with cucumber seed powder $\left(T_{6}\right)$. The fruits and nuts spreads were analyzed for the presence of phytochemicals $\beta$ carotene, polyphenols, tannins, flavonoids and antioxidant activity. The formulated fruits and nuts spreads were packed in polypropylene boxes, glass bottles and stored under refrigerated condition at $4^{\circ} \mathrm{C}$. $\beta$-carotene content was found to be high $(634.21 \mu \mathrm{g} / \mathrm{g})$ in Mango with Pumpkin seed powder spread $\left(\mathrm{T}_{1}\right)$, tannin content was higher $(52.61 \mathrm{mg} / \mathrm{g})$ in Papaya with Pumpkin seed powder spread $\left(T_{2}\right)$, flavonoid components were higher $(3.25 \mathrm{mg} / \mathrm{g})$ in Mango with Pumpkin seed powder spread ( $\left.T_{1}\right)$, and polyphenols content were found to be high $(59.33 \mathrm{mg} / \mathrm{g})$ in Papaya with Cucumber seed powder spread $\left(T_{5}\right)$. The antioxidant property was high in the Mango with Pumpkin seed powder spread $\left(T_{1}\right)$ when compared to all other treatments. Pumpkin seeds comprised of excellent amount of bioactive compounds. The pumpkin seed incorporated spread showed a high level of phytochemicals when compared to other spreads. This was ready to eat spread which had 3 months of shelf life under refrigerated condition is preferred for people of all age groups.
\end{abstract}

Keywords: Cucumber seeds, Nutraceutical compounds, Phytochemicals, Pumpkin seeds

\section{INTRODUCTION}

Spread is an edible paste that is added to other foods, which are generally consumed with bread, toasts and similar pastries such as pancakes and pistas. The fat content is more in the spread and it imparts shortening, richness, tenderness, improves mouthfeel, flavour and perception (Pareyt et al. 2009). The spread can be made with fruit pulp and enhanced with edible seed powders. The pumpkin, cucumber seeds are generally considered waste but are found to have many medical values and health benefits. The pumpkin belongs to the family of Cucurbitaceae. It is utilized as uncooked, cooked and roasted for domestic purpose. Pumpkin seeds are a rich source of protein, fibers, minerals such as iron, zinc, calcium, magnesium, manganese, copper and sodium, polyunsaturated fatty acid, phytosterol and vitamins. Health benefits of pumpkin seeds like reduc- 
tion in blood glucose, cholesterol levels, increased immunity and better functioning of the liver, prostate gland and gall bladder. Other established benefits include support for learning disabilities, depression, inflammation, cancer management and inhibition of parasites. Pumpkin seeds have high pharmacological activities such as antidiabetic, antifungal, antibacterial, antiinflammation, and antioxidant properties due to their high nutritional health protective values (Nkosi et al. 2006). Cucumber seeds are rich in bioactive compounds with nutracetical properties. It is an underutilized crop and considered as an agro waste (Montesano et al. 2018). The cucumber seeds have more protein, fat, minerals and calcium. It is an excellent coolant and diuretic in the summer seasons. It served as cooling, tonic, diuretic and anthelmintic effects. It has significant impact in diseases such as osteoporosis, osteoarthritis, cervical spondylosis. A seed of cucumber has cardiac glycosides, terpenoids, carbohydrates and saponins. The cardiac glycosides are used as anti-inflammatory properties (Shah and Seth 2011) and protect against lethal endotoxemia. Phytosterols also found in the seeds which has a significant hypocholesterolemic effects (Ezeodili et al., 2017). Cucumber seed contains more amounts of flavonoids, which is a cheap source of flavonoids. The flavonoids act as an antimicrobial, antioxidant, cytotoxicity, anti inflammatory as well as anti-tumour activity (Saxena et al., 2003). Antioxidant compounds such as phenoilc acids, polyphenols and flavonoids free radicals like peroxide, hydroperoxide or lipid peroxyl inhibit the oxidative stress that causes to degenerative disease (Nahak et al., 2014). Triterpenoid glycosides compound is found in the cucumber seeds which is responsible for the antioxidant and antiulcer activity (Gill and Bali et al., 2012). The mangoes (Mangifera indica L.) most important fruits, have more taste, aroma, and a good source of nutritional values (Ibarra et al., 2015). Mango contains sugars, fiber, minerals, vitamins and antioxidants (Tharanathan et al., 2006). It contains different types of volatile organic molecules such as terpenes, furanones, lactones and esters. It gives flavors to the fruits. Mango also contains vitamins $A, C, \beta$ - Carotene, Xanthophylls, Cis-9 and cis-15-octa decadienoic (Swaroop et al., 2018). It has maximum amounts of polyphenols, micronutrients found in plants which are used for specific health benefits. Polyphenols such as mangiferin, gallic acid, gallotannins, quercetin, isoquercetin, ellagic acid and $\beta$-glucogallin are used in an adequate amount. Mango pulp gives more amounts of phytochemicals which has an anti-inflammatory role in several chronic pathological disorders associated with inflammatory responses. It has more bioactive compounds which are used as anti diabetic and anticancer effects (Shahidi et al., 2017). Papaya fruits are a good source of nutrients include provitamins $A$, carotenoids, vitamin $C, \beta$ - caro- tene, lycopene, dietary minerals and dietary fiber. It is an iron and calcium rich fruits. Papain is also called as papaya proteinase enzyme present in the fruits. It possesses different types of carotenoids namely $\beta$ - carotene, lycopene, anthraquinones and glycosides, which has medicinal properties like anti-inflammatory, hypoglycemic, anti-fertility, hepatoprotective, wound healing, anti-hypersensitive and anti-tumor activity. Ripe papaya fruit is a laxative that assures of regular bowel movement (Yogiraj et al., 2014). Muskmelon is a good source of vitamins $A$ and $C$, minerals such as potassium, phosphorus and iron (Parveen et al. 2012, Priyanka et al., 2015). It has a soft, sweet juicy flesh with a musk like odor, but it is a highly perishable fruit (Aranceta, 2004). Muskmelon is known to have medicinal properties such as analgesic, anti-inflammatory, anticancer, antioxidant (Milind and Kulwant, 2011). The aim of the study was to formulate a nutraceutical enriched fruits and nuts spread and to analyze the biochemical compounds in the spreads.

\section{MATERIALS AND METHODS}

The fruit pulp or puree was extracted from the fruits like mango, papaya and muskmelon. Pumpkin seeds and cucumber seeds were machine dehulled and roasted at $150^{\circ} \mathrm{C}$ for 30 mins to remove the hard coating and to mask the raw odour of the seed. The roasted seeds were made into powder form. The fruit pulp was mixed with seed powder to get a thick consistency of spreads. The various treatments, i.e., a combination of fruits and nuts, are given in Table 1 . The standardized composition of seed powders (25\%) and sugar were incorporated with fruit pulp $(75 \%)$ to get a desirable consistency of fruits and Nuts spread based on the previous experiments. The fruits and nuts spreads were pasteurized at $60^{\circ} \mathrm{C}$ for $30 \mathrm{mins}$ to increase the quality of the product and the prepared products were organoleptically evaluated and kept under the refrigerated condition at $4^{\circ} \mathrm{C}$ for further analysis.

\section{$\beta$-carotene}

About 2-5g of food sample was taken and pulped well into smooth consistency using acetone and blended until the residue was colourless. The acetone extracts were pooled and transferred to a separating funnel containing about $20 \mathrm{ml}$ of distilled water and mixed. Carotenoid pigments get transferred from the lower aqueous layer to the upper petroleum ether layer. The upper layer was collected by using a separating funnel and then added petroleum ether $(20 \mathrm{ml})$ and mixed well to extract the $\beta$-Carotene. The procedure was repeated three to four times until the colour of the extract became colourless. The petroleum ether extract was pooled and washed once with $20 \mathrm{ml}$ distilled water in order to remove alkalinity. Filtered it into a conical flask 
through cotton wool over which anhydrous sodium sulphate was sprinkled to get water free solution. The final volume was made up to $50 \mathrm{ml}$ with petroleum ether and determined the solution's absorbance at 450nm in a UV - visual spectrophotometer using petroleum ether as blank.

\section{Calculation}

$\mu \mathrm{g}$ carotenoids $/ 100 \mathrm{gm}=\mathrm{OD}$ value $\times$ Total volume of extract $\times 100 / 0.2592 \times$ weight of the sample $\ldots$ Eq.1

\section{Phenol}

About $0.5-1 \mathrm{~g}$ of sample was weighed and grinded with a pestle and motor in 10 time volumes of $80 \%$ ethanol, centrifuged at $10,000 \mathrm{rpm}$ for 20 mins. The saved the supernatant was evaporated it to dryness. Dissolved the residue in a known volume of distilled water (5 $\mathrm{ml})$.different aliquots $(0.2-2 \mathrm{ml})$ was pipette out into test tubes. Make up the volume in each tube to $3 \mathrm{ml}$ with distilled water. $0.5 \mathrm{ml}$ of Folin-ciocateau reagent was added. After 3 mins $2 \mathrm{ml}$ of $20 \% \mathrm{Na}_{2} \mathrm{CO}_{3}$ solution was added to each tube. Mixed thoroughly. Placed the tubes in boiling water for $1 \mathrm{~min}$, cooled and measured at $650 \mathrm{~nm}$.prepared a standard curve using different concentrations of catechol. The standard curve finds out the concentration of phenols in the test sample and expresses as $\mathrm{mg}$ phenols $/ 100 \mathrm{~g}$ material.

\section{Tannins}

About $0.5 \mathrm{~g}$ of the powder sample was weighed and transferred to a $250 \mathrm{ml}$ conical flask. $75 \mathrm{ml}$ of water was added. Heated the flask gently and boil for 30mins. Centrifuged at $2000 \mathrm{rpm}$ for $20 \mathrm{~min}$ and collected the supernatant in $100 \mathrm{ml}$ volumetric flask and made up the volume. $1 \mathrm{ml}$ of the sample extract was transferred to a $100 \mathrm{ml}$ volumetric flask containing $75 \mathrm{ml}$ water. $5 \mathrm{ml}$ of Folin Ciocalteau reagent was added, then $10 \mathrm{ml}$ of sodium carbonate solution and dilute to $100 \mathrm{ml}$ with water. Shaked well. Read the absorbance at 700nm after $30 \mathrm{~min}$. Prepared a standard graph by using $0-100 \mu \mathrm{g}$ tannic acid. Calculate the tannin content of the samples as tannic acid equivalents from the standard graph.

\section{Total flavonoids}

Total flavonoids content of fruits and nuts spreads were determined using the Colorimetric method described by Willet (2002), with some modifications. Aqueous ethanol extracts $(0.5 \mathrm{ml}), 10 \%$ aluminium chloride $(0.1 \mathrm{ml}), 1 \mathrm{M}$ potassium acetate $(0.1 \mathrm{ml})$, and distilled water $(4.3 \mathrm{ml})$ were mixed. After incubation at room temperature for $30 \mathrm{~min}$, the absorbance was measured at $415 \mathrm{~nm}$ using a spectrophotometer. Quercetin was used to make the calibration curve. The calculation of total flavonoids content in the extracts was carried out in triplicate and the results were averaged.

\section{Determination of total antioxidant activity DPPH assay}

The radical scavenging activity of samples was determined by the 2, 2,-diphenyl-1-picrylhydrazyl (DPPH) radical scavenging assay. DPPH is a purple colored stable free radical that reacts with compounds that can donate a hydrogen atom. This method is based on the scavenging of DPPH through the addition of a radical species or an antioxidant that decolorizes the DPPH solution. The degree of discolouration indicates the scavenging potential of the antioxidant compounds. Different aliquots $(0.2-1 \mathrm{ml})$ of methanol extracts of each sample were pipetted out into test tubes and made up the volume in each test tube to $1 \mathrm{ml}$ with methanol. Then $2 \mathrm{ml}$ of freshly prepared DPPH solution (0.1 $\mathrm{mM})$ in methanol was added. The tubes mixed thoroughly and allowed to stand in the dark at room temperature. The absorbance decrease was determined after $30 \mathrm{~min}$ at $517 \mathrm{~nm}$ using a spectrophotometer. Methanol $(1 \mathrm{ml})$ replacing the plant extract serve as a negative control and methanol $(2 \mathrm{ml})$ replacing the DPPH reagent serve as sample blanks. The percentage of radical scavenging activity (\% RSA) or percentage inhibitions of DPPH of the methanolic extract of the samples were calculated by the following formula.

$\%$ RSA $=\frac{\left\{A_{(C)}-\left(A_{(S)}\right\}\right.}{A_{(C)}} \times 100 \quad \ldots . . E q .2$

Where $A_{(C)}$ - absorbance of negative control, $A_{(S)^{-}} a b-$ sorbance of sample

Then graphs were plotted between the percentages of radical scavenging activity and the different concentrations of methanolic extracts of samples. Ascorbic acid was used as a standard (positive control) and the percentage radical scavenging activity of the different concentration of the ascorbic acid standard was estimated by the same method and formula used for the samples. Then graphs were plotted between the percentage of radical scavenging activity and the different concentrations of standards, then the slopes of the standard graph were calculated and the radical scavenging activity of the samples was expressed as mg of ascorbic acid equivalent $100 \mathrm{~g}^{-1}$ of sample in fresh and dry weight basis. (Muruganantham et al 2016)

\section{Statistical analysis}

The statistical analysis was performed by AGRESAGDATA for one way analysis of variance. The results are the average of the four replicates and their Standard deviation.

\section{RESULTS AND DISCUSSION}

\section{Phytochemical analysis}

Table 2 shows phytochemicals for the presence of $\beta-$ Carotene, tannin, flavonoids, polyphenols and antioxi- 


\begin{tabular}{ll}
\hline \multicolumn{2}{l}{ Table 1. Combination of fruits and nuts spread. } \\
\hline Treatment & Fruits (75\%) + seed powder (25\%) \\
\hline $\mathrm{T}_{1}$ & Mango + Pumpkin seed powder \\
$\mathrm{T}_{2}$ & Papaya + Pumpkin seed powder \\
$\mathrm{T}_{3}$ & Muskmelon + Pumpkin seed powder \\
$\mathrm{T}_{4}$ & Mango + Cucumber seed powder \\
$\mathrm{T}_{5}$ & Papaya + Cucumber seed powder \\
$\mathrm{T}_{6}$ & Muskmelon + Cucumber seed powder \\
\hline
\end{tabular}

dant activity were analyzed in the fruits and nuts spreads. Pumpkin seed and cumber seeds contained more nutritional compounds and fruits like mango, papaya and muskmelon contained more phytochemicals.

\section{$\boldsymbol{\beta}$ - Carotene}

The carotenoid content ranged from $301.93 \mu \mathrm{g} / \mathrm{g}$ to $623.21 \mu \mathrm{g} / \mathrm{g}$ in all treatments. The mango with pumpkin seed powder spread $\beta$-carotene content $(623.21 \mu \mathrm{g} / \mathrm{g})$ and the lowest was found in muskmelon with cucumber seed powder spread $(301.93 \mu \mathrm{g} / \mathrm{g})$ with respect to the content of these substances in the pulp (Table 2). Silva et al. (2014) reported that the carotene retention of mango fruit powder was $196.15 \mu \mathrm{g} / \mathrm{g}$. Renna et al. (2013) reported that the boiling step before the final cooking during carrot jam processing probably improved $\beta$ carotene retention in a jam. Rozan (2017) also stated that the addition of turmeric as an ingredient of jam formulation significantly improved carotenoid retention.

\section{Tannin}

Tannin content tends to decrease in fruits and nuts spreads after processing. Among the treatments, the tannin content was more in the papaya with pumpkin seed powder spread about $52.61 \mathrm{mg} / \mathrm{g}$ and the lowest value was $31.20 \mathrm{mg} / \mathrm{g}$ noticed in muskmelon with

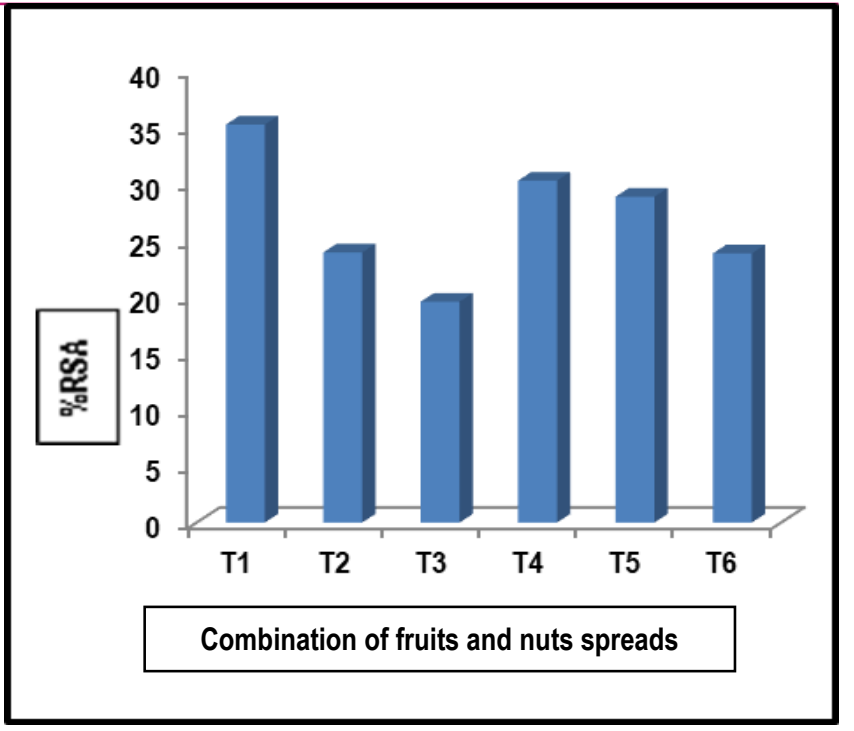

Fig. 1. Antioxidant activity of fruits and nuts spreads (\% $R S A)$.

cucumber seed powder spread. (Table 2). Sinha et al. (2012) was observed that upon cooking, the formation of condensed tannins decreased the antioxidant activity of the phenolic fraction. During ambient storage, whitefleshed cloudy guava nectar deteriorates in quality due to nonenzymatic browning reactions through the involvement of ascorbic acid and tannins (Chen et al. 1994). In this study, tannin content decreased during processing and did not affect the storage characteristics of processed spread

\section{Flavonoids}

Flavonoids content of the fruits and nuts spreads ranged between $1.05 \mathrm{mg} / \mathrm{g}$ to $3.25 \mathrm{mg} / \mathrm{g}$. Noticeable amount of rise in flavonoids was seen in all the treatment. A higher amount of flavonoid was noticed in mango with pumpkin seed powder spread combination of fruits and nuts spreads. It was about $3.25 \mathrm{mg} / \mathrm{g}$ and muskmelon with cucumber seed powder spread shows the least amount of flavonoids found was around

Table 2. Phytochemicals of fruits and nuts spreads.

\begin{tabular}{lllll}
\hline Treatment & $\beta$-Carotene $(\boldsymbol{\mu g} / \mathbf{g})$ & Tannin $(\mathbf{m g} / \mathbf{g})$ & Flavonoids $(\mathbf{m g} / \mathbf{g})$ & Poly phenols (mg/g ) \\
\hline $\mathrm{T}_{1}$ & $623.21 \pm 0.87^{\mathrm{f}}$ & $48.93 \pm 0.46^{\mathrm{d}}$ & $3.25 \pm 0.03^{\mathrm{f}}$ & $56.21 \pm 1.58^{\mathrm{b}}$ \\
$\mathrm{T}_{2}$ & $501.75 \pm 0.80^{\mathrm{d}}$ & $52.61 \pm 0.96^{\mathrm{e}}$ & $2.71 \pm 0.01^{\mathrm{d}}$ & $58.03 \pm 0.71^{\mathrm{c}}$ \\
$\mathrm{T}_{3}$ & $324.54 \pm 0.66^{\mathrm{b}}$ & $34.62 \pm 0.65^{\mathrm{b}}$ & $1.65 \pm 0.06^{\mathrm{b}}$ & $44.98 \pm 1,31^{\mathrm{a}}$ \\
$\mathrm{T}_{4}$ & $604.75 \pm 0.34^{\mathrm{e}}$ & $44.73 \pm 0.79^{\mathrm{c}}$ & $3.04 \pm 0.03^{\mathrm{e}}$ & $57.85 \pm 1.88^{\mathrm{c}}$ \\
$\mathrm{T}_{5}$ & $487.53 \pm 0.61^{\mathrm{c}}$ & $50.17 \pm 1.05^{\mathrm{d}}$ & $2.15 \pm 0.06^{\mathrm{c}}$ & $59.33 \pm 1.08^{\mathrm{d}}$ \\
$\mathrm{T}_{6}$ & $301.93 \pm 0.03^{\mathrm{a}}$ & $31.20 \pm 0.34^{\mathrm{a}}$ & $1.05 \pm 0.01^{\mathrm{a}}$ & $45.86 \pm 0.65^{\mathrm{a}}$ \\
\hline
\end{tabular}

*Values are means of 4 replicates; *Means in the same column followed by different superscripts are significantly different at $P<0.05$ 
$1.05 \mathrm{mg} / \mathrm{g}$ (Table 2). Wall-metrano et al. (2020) evaluated that the flavonoids content of mango pulp was 4.0mgQE/g. Sinha et al. (2012) stated that the factors like modification of the structure of the flavonoid are substitution by different sugars are acids may deeply affect the biological activity of flavonoids, and in a sense, different processing of the fruits may also influence the beneficial properties or human health.

\section{Poly phenols}

The polyphenol content of papaya with cucumber seed powder spread was $59.33 \mathrm{mg} / \mathrm{g}$ which was considered to the higher than other treatments. The muskmelon with pumpkin seed powder spread showed a very low amount of polyphenol content of $44.98 \mathrm{mg} / \mathrm{g}$ (Table 2). During jam cooking, the cell structure is ruptured and the sensitive compounds, especially phenols, become susceptible to non-enzymatic oxidation (Patras et al. 2010). Lobo et al. (2017) showed that mango pulps total phenol content is $46.18-116.93 \mathrm{mg}$ gallic acid/100 g. Rozan et al. (2017) investigated that the reduction in individual phenolic compounds was compatible with the decrease of total phenolic content. Except for catechin, sinapic and cinnamic acid, turmeric addition to carrot during jam processing resulted in a significant increase in phenolic compounds.

\section{Antioxidant activity}

Fig. 1 shows about 20 to 40 percent of antioxidant activity increased in all the treatments. Higher percentage of $(40 \%)$ antioxidant activity was found in mango with pumpkin seed powder spread whereas minimum level of antioxidant activity like $20 \%$ noted in muskmelon with pumpkin seed powder spread. Abbasi et al. (2017) reported that the antioxidant capacity of mango pulp was $66.53 \%$. Montesano et al. (2018) reported that highest antiradical capacity was recorded for the pumpkin powders incorporated beverage and the lowest value was determined for the carrot powder incorporated sample.

\section{Conclusion}

The pumpkin seeds and cucumber seeds were considered underutilized seeds but they had more nutritional values, bioactive compounds and nutraceutical properties. The components were used in the spread to increase the nutraceutical value of the spread. The spreads were highly preferred for all age groups and preferred them as best ready to use food. The fruits and nuts spread contain more amounts of bioactive compounds.

\section{Conflict of interest}

The authors declare that they have no conflict of interest.

\section{REFERENCES}

1. Abbasi, A. M., Liu, F., Guo, X., Fu, X., Li, T., \& Liu, R. H. (2017) Phytochemical composition, cellular antioxidant capacity and antiproliferative activity in mango (Mangifera indica L.) pulp and peel. International Journal of Food Science \& Technology, 52(3), 817-826.

2. Aranceta, J., (2004). Fruits and vegetables. Archivos Latinoamericanos de Nutricion, 54(2 Suppl 1), 65-71.

3. Chen N. L., Lee. C. Y. \& Wu. J, S. B. (1994). An evaluation of possible mechan isnrs $f$ or norl enzymatic browning ir: guava nectar during storage. Forsd, Science, (ShihP' in K'o IJ.suah) (Tairvan), 2 I, 293.

4. Ezeodili, V.K., Ihim, A.C., Ogbodo, E.C., Ezeugwunne, I.P., Analike, R.A., Onah, C.E., Amah, U.K., Okwara, J.E., Ezego, A.I., Ugwu, M.C., Oguaka, V.N., Asebioyo, S.J. and Meludu, S.C. (2017). Effect of cucumber consumption on serum lipid profile and liver aspartate transaminase and alanine transaminase in apparently healthy undergraduate students. International Journal of Basic, Applied and Innovative Research, 6(2), 38-45

5. G. Nahak, M. Suar, and R. K. Sahu (2014). Antioxidant potential and nutritional values of vegetables: A review, Res. J. of Medicinal Plant., 8(2), 50-81

6. Ibarra-Garza, Ingrid P, Perla A Ramos-Parra, Carmen Hernández-Brenes, and Daniel A Jacobo-Velázquez (2015). Effects of postharvest ripening on the nutraceutical and physicochemical properties of mango (Mangifera indica L. cv Keitt). Postharvest Biology and Technology 103, 45-54.

7. Lobo F.A., Nascimento M.A., Domingues J.R., Falcão D.Q., Hernanz D., Heredia F. \& de Lima Araujo, K. G. (2017). Foam mat drying of Tommy Atkins mango: Effects of air temperature and concentrations of soy lecithin and carboxymethylcellulose on phenolic composition, mangiferin, and antioxidant capacity. Food Chem., 221, 258266.

8. Saxena, M., Saxena, J., Nema, R., Singh, D. \& A. Gupta, (2013). Phytochemistry of medicinal plants. J. of Pharmacog. and Phytochem., 1(6), 168-180.

9. Mahmoud A. Rozan (2017). Egypt carotenoids, phenolics, antioxidant activity and sensory attributes of carrot jam: Effect of turmeric additio. J. Food Sci., 45, $113-123$

10. Milind, P. \& Kulwant, S. (2011). Musk melon is eat-must melon. International Research Journal of Pharmacy, 2(8), 52-57.

11. Montesano, D., Blasi, F., Simonetti, M.S., Santini, A. \& Cossignani, I. (2018). Chemical and nutritional characterization of seed oil from Cucurbita maxima L. (var. Berrettina) pumpkin. Foods, 7(3), 30-33.

12. Muruganantham, N., Solomon, S., \& Senthamilselvi, M. M. (2016). Anti-oxidant and anti-inflammatory activity of Cucumis sativas (cucumber) flowers. Int. J. Pharm. Sci. Res., 7(4), 1740-1745.

13. Gill, N. S. \& Bali, M. (2012). Evaluation of antioxidant, antiulcer activity of 9-beta-methyl-19-norlanosta-5-enetype glycosides from Cucumis sativus seeds, Res. J. of Medicinal Plant, 6 (4), 309-317

14. Nirmal K. Sinha Jiwan S. Sidhu Jozsef Barta' James S. B. \& Wu M. (2012). Pilar Cano Handbook of Fruits and Fruit Processing. Second Edition Edited by This edition first published 2012 C 2012 by John Wiley \& Sons, Ltd. 
First edition published $2006 \mathrm{C}$ Blackwell Publishing

15. Nkosi C.Z. \& Opaku A.R. (2006). Antioxidant effects of pumpkin seeds (Cucurbita pepo) protein isolate in ccl4 Included liver injury in low protein fed rats. Phytother Res., 20(11), 935-940. doi: 10.1002/ptr.1977

16. Pareyt, B., Talhaoui, F., Kerckhofs, G., Brijs, K., Goesaert, H., Wevers, M. \& Delcour, J.A. (2009). The role of sugar and fat in sugar-snap cookies: Structural and textural properties. Journal of Food Engineering. 90, 400-408

17. Parveen, S., M. A. Ali, M. Asghar, A. R. Khan and A. Salam ( 2012). Physico-chemical changes in muskmelon (cucumis melo I.) as affected by harvest maturity stage. Journal of Agricultural Research, 50(2), 249-260.

18. Patras, A., Brunton, N.P., O'Donnell, C. \& Tiwari B.K. (2010). Effect of thermal processing on anthocyanin stability infoods; mechanisms and kinetics of degradation. Trends in Food Science \& Technology, 21, 3-11

19. Priyanka, D., S. Sindhoora, P. Vijayanand, S. Kulkarni \& S. Nagarajan (2015). Influence of thermal processing on the volatile constituents of muskmelon puree. Journal of Food Science and Technology, 52(5), 3111-3116.

20. Renna, M., Bernardo. P., Maria, C.P.S., Francesco S. \& Maria G. (2013). Comparison of two jam making methods to preserve the quality of colored carrots. LWT - Food Science and Technology, 53, 547-554.
21. Shah, B.N., and Seth, A.K. (2011). Screening of Lagenaria siceraria fruits for their analgesic activity. Romanian Journal of Biology -Plant Biology, 55(1), 23-26

22. Shahidi, F. (2004). Functional foods: Their role in health promotion and disease prevention. J. Food Sci., 69, 146149.

23. Silva L, Figueiredo E, Ricardo N, Vieira I, Figueiredo $R$, Brasil I. \& Gomes C. (2014). Quantification of bioactive compounds in pulps and byproducts of tropical fruits from Brazil. Food Chem., 143, 398-404.

24. Swaroop, A., Bagchi, M., Moriyama, H. \& Bagchi, D. (2018). Health benefits of mango (Mangifera indica L.) and mangiferin, Jpn. J. Med., 1(2), 149-154.

25. Tharanathan, R., Yashoda, H. \& Prabha, T.N. (2006). Mango (Mangifera indica L.), "The king of fruits"- An overview. Food Reviews International, 22(2), 95e123.

26. Wall-Medrano, A., Olivas-Aguirre, F. J., Ayala-Zavala, J. F., Domínguez-Avila, J. A., Gonzalez-Aguilar, G. A., Herrera-Cazares, L. A. \& Gaytan-Martinez, M. (2020). Health benefits of mango by-products. Food Wastes and By products: Nutraceutical and Health Potential, 159-191

27. Yogiraj, V., Goyal, P. K., Chauhan, C. S., Goyal, A. \& Vyas, B. (2014). Carica papaya Linn: an overview. International Journal of Herbal Medicine, 2(5), 01-08. 